\title{
Deep dyslexia and the right-hemisphere hypothesis: What's left?
}

\author{
DEREK BESNER \\ University of Waterloo, Waterloo, Ontario N2L 3G1, Canada
}

\begin{abstract}
One account of the residual reading abilities seen in deep dyslexia asserts that they entirely reflect the operation of an intact right-hemisphere reading system rather than a partially disabled left-hemisphere reading system. Evidence from experiments on normal subjects suggests that there is no representation in the right hemisphere for words that denote color that can be accessed by visual presentation. Examination of several deep dyslexic's color-word reading abilities reveals little deficit. This suggests that the right-hemisphere account of the residual reading abilities seen in deep dyslexia is not a sufficient one.
\end{abstract}

In recent years, considerable effort has been expended in investigating the deficits seen in "deep" or "phonemic" dyslexia, a form of acquired dyslexia resulting from left-hemisphere damage (e.g., Andreewsky \& Seron, 1975; Kapur \& Perl, 1978; Marin, Saffran, \& Schwartz, 1975; Marshall \& Newcombe, 1966; Morton \& Patterson, 1980a; Newcombe \& Marshall, 1980a, 1980b; Patterson, 1978, 1979, 1980; Patterson \& Marcel, 1977; Saffran, Boygo, Schwartz, \& Marin, 1980; Saffran \& Marin, 1977; Saffran, Schwartz, \& Marin, 1976; Sasanuma, 1980; Shallice \& Warrington, 1975). Briefly, these patients show the following deficits when asked to read single words (or nonwords) aloud, without time pressure: (1) semantic errors (e.g., tulip $\rightarrow$ crocus), (2) visual errors (e.g., scandal $\rightarrow$ sandal), (3) derivational errors (e.g., wrestle $\rightarrow$ wrestler), (4) almost total inability to read orthographically regular but unfamiliar letter strings, such as nonsense words (e.g., DAP, ISH, LAR, FON) and nonword homophones of real words (e.g., BRANE, SHERT), and (5) reading as a function of word class, with best performance on highly imageable nouns and worst performance on function words.

Attempts to explain these deficits within the context of information processing-based models of reading can be broadly classified as either left-hemisphere or righthemisphere theories. Left-hemisphere theories (e.g., Morton \& Patterson, 1980b; Newcombe \& Marshall, 1980b; Shallice \& Warrington, 1980) assume that the residual reading abilities of these patients reflect the operation of the (or a) disabled left-hemisphere system. In contrast, the strong version of the right-hemisphere theory asserts that deep dyslexics' left hemispheres are not involved in any of the processes up to and including the extraction of meaning from print, but they may function as an interface between the right-hemisphere

This work was supported in part by Grant U0051 from the Natural Sciences and Engineering Research Council of Canada to the author. I am grateful to Graham Ratcliff, Karalyn Patterson, Phil Merikle, and Max Coltheart for discussion. semantic system and the left-hemisphere speech production system. The residual reading ability of these patients is therefore assumed to reflect and be limited by the competence of an intact right-hemisphere reading system (e.g., Coltheart, 1980, Note 1; Saffran et al., 1980). The relevance of the deficits seen in deep dyslexia to an understanding of the processes involved in normal fluent reading depends, therefore, upon the extent of the correspondence between the hemisphere(s) responsible for normal reading and the one(s) responsible for the residual reading ability seen in dyslexic patients.

One way to evaluate the right-hemisphere hypothesis is to search the experimental literature for reading tasks that normal subjects' right hemispheres cannot perform. If deep dyslexics can do tasks that the literature indicates cannot be performed by the right hemisphere, then it would follow that these patients cannot be reading only with their right hemispheres. ${ }^{1}$

With this aim in mind, the results of some experiments conducted by Schmit and Davis'(1974) are of particular interest. They started from the premise that the right hemisphere is incapable of carrying out what they called "verbal" analysis of written words. They reasoned that if normal subjects were presented with brief exposures of Stroop stimuli and asked to make a manual response indicating the color of the ink, there would be no interference from the conflicting information contained in the word as long as the information was presented to the right hemisphere. What Schmit and Davis found was perfectly consistent with this view; as long as only the right hemisphere was involved in the analysis of the signal and the production of the response, the time to respond to the color patch in the control condition was no different from the time to respond to the ink color in the conflict condition. In contrast, right visual field presentation showed a large Stroop effect regardless of which hand was used to make the response, as did left visual field presentation, provided that the response was with the right hand, thereby necessitating a transfer of information from right to left 
Table 1

Color-Word Reading Data From Four Deep Dyslexics

\begin{tabular}{|c|c|c|c|c|}
\hline & P.W. & D.E. & B.B. & $\mathbf{R}$. \\
\hline brown & $*$ & $*$ & $*$ & "it's not black" \\
\hline grey & $*$ & $*$ & $*$ & (mimed salt and pepper?) \\
\hline red & $*$ & $*$ & $*$ & $*$ \\
\hline blue & $*$ & $*$ & * & $*$ \\
\hline black & $*$ & $*$ & $*$ & "not really red" \\
\hline purple & $*$ & $*$ & * & $*$ \\
\hline white & $*$ & $*$ & $*$ & "greens" (to eat) \\
\hline green & $*$ & $*$ & * & $*$ \\
\hline yellow & $*$ & $*$ & $*$ & "orange" \\
\hline mauve & $*$ & "same as purple but a little bit darker" & omission & omission \\
\hline pink & $*$ & $*$ & $*$ & "red?" \\
\hline
\end{tabular}

*Correct reading.

hemisphere so as to control one of three different rightfingered responses.

We know, of course, from more recent literature, that Schmit and Davis (1974) started from too strong a premise, since there is now evidence that the right hemisphere of normal right-handed subjects can perform a visual lexical decision task on some classes of words at least as well as the left hemisphere (e.g., Day, 1977, 1979). A slightly different interpretation that can be given to Schmit and Davis' results, therefore, is that the right hemisphere simply does not represent color words in an internal lexicon that can be accessed by visual presentation. $^{2}$

If this interpretation is correct, then the righthemisphere hypothesis makes a very strong and straightforward prediction; deep dyslexics should not be able to read words correctly when they are the names of colors or make semantic errors, because they are reading with their right hemisphere and the right hemisphere contains no representations ${ }^{3}$ for color words that can be accessed by visual presentation. At best, the deep dyslexics should make either omissions or, perhaps, visual errors.

Fortunately, a recent report (Coltheart, Patterson, \& Marshall, 1980) contains corpora of both correct and incorrect reading responses to single words from four deep dyslexic patients; an examination of these responses is instructive.

The first patient, P.D., read six of the seven color words in the Brown and Ure (1969) list correctly; he made an omission to one of them.

The second and third error corpora, that for P.W. and D.E., contain only those words to which some sort of paralexic response was made (e.g., semantic, visual, derivational, and substitution). None of these was a color word.

The final patient, K.F., correctly read all eight of the color words contained in the AA frequency range from the Thorndike-Lorge (1944) list. He also read six of seven color words in the Brown and Ure (1969) list. His only "error" consisted of responding "color" to the word "yellow" and then pointing to it.
Encouraged by these findings, a more formal test was carried out ${ }^{4}$ by asking four deep dyslexic patients to read from a set of 71 words unrelated to color except for 11 color names randomly distributed throughout the list. The data can be seen in Table 1 .

These results clearly indicate that at least some patients classified as deep dyslexics are quite capable of either correctly reading color words or rendering a semantic interpretation in the correct domain.

\section{DISCUSSION}

If the interpretation given here for Schmit and Davis' (1974) results is accepted, then the reading responses of the dyslexic patients to color words constitute evidence that the righthemisphere hypothesis is not a sufficient account of all the reading abilities of all deep dyslexics.

\section{REFERENCE NOTE}

1. Coltheart, M. Phonemic dyslexia: Some comments on its interpretation and its implications for the study of normal reading. Paper presented at the meeting of the International Neuropsychology Society, Oxford, 1977.

\section{REFERENCES}

Andreewsky, E., \& Seron, X. Implicit processing of grammatical rules in a case of agrammatism. Cortex, 1975, 11, 379-390.

Brown, W. P., \& Ure, D. M. J. Five rated characteristics of 650 word association stimuli. British Journal of Psychology, $1969,60,223-250$.

Caplan, L., \& Hedley-White, T. Cueing and memory dysfunctions in alexia without agraphia. Brain, 1974, 97, 251-262.

Coltheart, M. Deep dyslexia: A right hemisphere hypothesis. In M. Coltheart, K. E. Patterson, \& J. C. Marshall (Eds.), Deep dyslexia. London: Routledge \& Kegan Paul, 1980.

Coltheart, M., Patterson, K. E., \& Marshall, J. C. (Eds.). Deep dyslexia. London: Routledge \& Kegan Paul, 1980.

DAY, J. Right-hemisphere language processing in normal right handers. Journal of Experimental Psychology: Human Perception and Performance, 1977, 3, 518-528.

DAY, J. Visual half field word recognition as a function of syntactic class and imageability. Neuropsychologia, 1979, 17, 515-518.

Kapur, N., \& Perl, N. T. Recognition reading in paralexia. Cortex, 1978, 14, 439-443. 
Marin, O. S. M., Saffran, E. M., \& Schwartz, M. F. Dissociation of language in aphasia: Implications for normal function. Annals of the New York Academy of Sciences, 1975, 280, 868-884.

Marshall, J. C., \& Newcombe, F. Syntactic and semantic errors in paralexia. Neuropsychologia, 1966, 4, 169-176.

Morton, J., \& Patterson, K. E. Little words-No! In M. Coltheart, K. E. Patterson, \& J. C. Marshall (Eds.), Deep dyslexia. London: Routledge \& Kegan Paul, 1980. (a)

Morton, J., \& PAtTerson, K. E. A new attempt at an interpretation, or an attempt at a new interpretation. In $\mathbf{M}$. Coltheart, K. E. Patterson, \& J. C. Marshall (Eds.), Deep dyslexia. London: Routledge \& Kegan Paul, 1980. (b)

Newcombe, F., \& Marshall, J. C. Response monitoring and response blocking in deep dyslexia. In M. Coltheart, $\mathbf{K}$. E. Patterson, \& J. C. Marshall (Eds.), Deep dyslexia. London: Routledge \& Kegan Paul, 1980. (a)

Newcombe, F., \& Marshall, J. C. Transcoding and lexical stabilization in deep dyslexia. In M. Coltheart, K. E. Patterson, \& J. C. Marshall (Eds.), Deep dyslexia. London: Routledge \& Kegan Paul, 1980. (b)

Patte rson, K. E. Phonemic dyslexia: Errors of meaning and the meaning of errors. Quarterly Journal of Experimental Psychology, 1978, 30, 587-607.

Patterson, K. E. What is right with "deep" dyslexic patients? Brain and Language, 1979, 8, 111-129.

Patterson, K. E. Derivational errors. In M. Coltheart, K. E. Patterson, \& J. C. Marshall (Eds.), Deep dyslexia. London: Routledge \& Kegan Paul, 1980.

Patterson, K. E., \& Marcel, A. J. Aphasia, dyslexia and the phonological recoding of written words. Quarterly Journal of Experimental Psychology, 1977, 19, 307-318.

Saffran, E. M., Boygo, L. C., Schwartz, M. F., \& Marin, O. S. M. Does deep dyslexia reflect right hemisphere reading? In M. Coltheart, K. E. Patterson, \& J. C. Marshall (Eds.), Deep dyslexia. London: Routledge \& Kegan Paul, 1980.

Saffran, E. M., \& Marin, O. S. M. Reading without phonology: Evidence from aphasia. Quarterly Journal of Experimental Psychology, 1977, 29, 515-525.

Saffran, E. M., Schwartz, M. F., \& Marin, O. S. M. Semantic mechanisms in paralexia. Brain and Language, 1976, 3, 256-265.

Sasanuma, S. Acquired dyslexia in Japanese: Clinical features and underlying mechanisms. In M. Coltheart, K. E. Patterson, \& J. C. Marshall (Eds.), Deep dyslexia. New York: Routledge \& Kegan Paul, 1980.

Schmiт, V., \& Davis, R. The role of hemispheric specialization in the analysis of Stroop stimuli. Acta Psychologia, 1974, 38, 149-158.

Shallice, T., \& Warrington, E. K. Word recognition in a phonemic dyslexic patient. Quarterly Journal of Experimental Psychology, 1975, 27, 187-199.

Shallice, T., \& Warrington, E. K. Single and multiple component central dyslexic syndromes. In M. Coltheart, K. E. Patterson, \& J. C. Marshall (Eds.), Deep dyslexia. London: Routledge \& Kegan Paul, 1980.

Thorndike, E. L., Lorge, I. The teacher's word book of 30,000 words. New York: Teachers' College, 1944.

\section{NOTES}

1. Provided, of course, that there is no right-hemisphere takeover of left-hemisphere function.

2. It might be argued that the failure to find Stroop effects with left visual field presentation and a left-hand response need not necessarily be interpreted as evidence that the righthemisphere lexicon does not represent color words. It might only be evidence that access to color words in the right hemisphere is very slow, so slow, in fact, that information about the color of the word is available for a response before the word itself is accessed. This would result in no Stroop interference.

The difficulty with this explanation is that it predicts that if the task is reversed, so that the subject responds to the word and ignores its color, then there should be more interference with left than with right visual field presentation. Consider why this should be so. When subjects respond to color and attempt to ignore the word in the right visual field condition, there is a large Stroop effect, suggesting that the word is available before the color and is therefore able to interfere with a response based on color. This means that if the task is reversed, then at least some of the time, the word will be available before the color, and no interference will result. With left visual field presentation, however, it has been assumed that there is no Stroop interference when the response is to color because the color information is always faster than the word information. When the subject responds to the word and ignores the color, he will thus have more difficulty given left than given right visual field presentation because color will always be available before the word in the left visual field condition and thus will always interfere, but it will only sometimes be available before the word with right visual field presentation and thus only sometimes interfere.

The data from a second experiment by Schmit and Davis (1974) do not support this alternative explanation of why there is no right-hemisphere-based Stroop interference when responses are made to color and words are ignored. Instead of finding that color interfered more with left than with right visual field presentation, as the alternative explanation would seem to require, Schmit and Davis found that when the response was to be based on the word and its color was to be ignored, the amount of interference was independent of visual field. This result is to be expected if the right hemisphere contains no representations for color words and, therefore, all color words must ultimately access the left hemisphere in order to be recognized and responded to.

3. Note, however, that there is no reason to assume that all subjects are equivalent with respect to what is represented in left and right hemispheres; there might well be people who do represent color words in a right-hemisphere lexicon (see, for example, Caplan \& Hedley-White, 1974). It would therefore be worth testing as many deep dyslexics as possible; if some of these patients could not read color words, then the observations reported here would not necessarily falsify a strong version of the right-hemisphere hypothesis.

4. I am grateful to K. E. Patterson for these data.

(Received for publication August 31, 1981.) 